\title{
The Poetic Transmission of Zen Buddhism
}

\author{
Yong Zhi ${ }^{1}$ \\ ${ }^{1}$ School of Public Adminstration, Zhengzhou University, China \\ Correspondence: Yong Zhi, School of Public Adminstration, Zhengzhou University, Zhengzhou, China. Tel: \\ 1-203-435-0194. E-mail: yongzhi3000@gmail.com
}

\author{
Received: September 14, 2012 Accepted: January 30, 2013 Online Published: March 8, 2013 \\ doi:10.5539/ach.v5n2p25 \\ URL: http://dx.doi.org/10.5539/ach.v5n2p25
}

\begin{abstract}
This paper intends to understand the experience of enlightenment in Zen Buddhism from a perspective of poetics. Enlightenment is understood as an existential breakthrough, which delivers people from the habitual or conventional mind set into new horizon of consciousness. This breakthrough takes place in one's overall consciousness rather than only in cognitive thought. Therefore, it cannot be adequately described on an abstract level with a conceptual paradigm. The poetic language provides a significant alternative for capturing this leap and revealing the spiritual meaning and the practical wisdom of enlightenment. Enlightenment, as concrete experiences in the "flux" of the mind, can be most directly expressed and effectively transmitted in poetic language.
\end{abstract}

Keywords: philosophy, Asian religions, Buddhism, Zen, language, poetry, Chinese poetics, enlightenment, higher consciousness

The link between spirituality and poetry has long been known by all religious traditions, from the Vedic to the Psalms, while the relationship between poetry and philosophy has since the ancient Greeks fascinated both philosophers and poets. We will see in the case of Zen Buddhism, poetry is intrinsic to the spiritual practice, both as the expression of and as the path to enlightenment which will be seen as poetic leaps into higher consciousness.

\section{The Meaning of Enlightenment and the Poetic Language}

We will start our discussion by analyzing the meaning of enlightenment from Zen's perspective and see how it can be better captured in poetic language rather than conventional language. One essential aspect of enlightenment is emancipation, as Suzuki writes:

Zen is discipline in enlightenment. Enlightenment means emancipation. And emancipation is no less than freedom. We talk very much these days about all kinds of freedom, political, economic, and otherwise, but these freedoms are not at all real. As long as they are on the plane of relativity, the freedoms or liberties we glibly talk about are far from being such. The real freedom is the outcome of enlightenment (Suzuki, 1973).

One question is from what is one emancipated? Suzuki indicates that liberation from relative things is not profound or authentic enough to constitute enlightenment. According to Suzuki, the real freedom in enlightenment is "free from all forms, inner and outer" (Suzuki, 1962). Suzuki thinks that those linguistic and cultural forms artificially condition the mind, and the path to enlightenment is by ridding the mind of the social filter of language, and achieves "liberation from linguistic and cultural conditioning" (Wright, 1992). However, based on an earlier discussion, this enterprise is rendered impossible from the prevalent standpoint of modern philosophy, which considers language indispensable in any kind of experience.

Suzuki sees the tension between Zen and language and realizes that the key to enlightenment lies in the resolution of the tension, although his criticism of language does not really accomplish this. Various philosophical and spiritual thinkers, such as Heidegger and the Daoist founders, have discussed the critical role of language and discovered that language is the double-edged sword that discloses and conceals, liberates and entraps. It both leads the way in peoples' searches for meaning and meanwhile leaves traces to mislead and traps for people to fall. From Zen's perspective, enlightenment is the act of disclosing and speaking, which breaks free from what has been disclosed and spoken. Enlightenment is not the emancipation from language, but the emancipation from what has been spoken. It is the breakthrough or the leap toward a new horizon beyond what 
has been disclosed. The act of disclosing and speaking is always against the backdrop of the established. From this perspective, language is the gate to enlightenment, although the door in the gate seems to be closed until one breaks it open, therefore, Zen calls it the gate-less gate. Enlightenment is the movement of language as it constantly makes leaps from what it establishes.

Enlightenment not only delivers people from the habitual world but also reveals new consciousness in what Zen calls illumination. It thus incorporates two integral dimensions: emancipation and illumination, as the act of speaking transcends what has been said and discloses a new world. Emancipation clears up the mind that may be stuffed with habitual thoughts, while illumination is the formation of new consciousness, which is the emergence of the new horizon against the background of the disclosed. With the new consciousness, enlightenment is considered the turning point in one's life, which frees the mind from established forms and opens it to new forms. Suzuki puts it this way:

The essence of Zen Buddhism consists in acquiring a new viewpoint of looking at life and things generally. By this I mean that if we want to get into the inmost life of Zen, we must forego all our ordinary habits of thinking which control our everyday life (Suzuki, 1962).

The "ordinary habits of thinking" is in the domain of the disclosed or the spoken. Enlightenment is a new disclosure against the background of the already disclosed world. This event may take place so "suddenly" that no trace of the movement can be found. In other words, the new illumination cannot be logically derived from what has been disclosed and spoken. The enlightened one has to cross over a chasm that cannot be logically conceived. The term "leap" most appropriately describes this movement, as Suzuki notes:

That the process of enlightenment is abrupt means that there is a leap, logical and psychological, in the Buddhist experience. The logical leap is that the ordinary process of reasoning stops short, and what has been considered irrational is perceived to be perfectly natural, while the psychological leap is that the border of consciousness are overstepped and one is plunged into the Unconscious which is not, after all, unconscious (Suzuki, 1969).

Through the leap, the practitioner can either attain the illumination as a new consciousness, or retreat into emptiness as an "Unconsciousness" which we will discuss later. In both occasions, when the leap occurs, for a moment, there is no available paradigm to make sense of it, because the enlightened encounters a completely new horizon.

This provides the key to understand the intrinsic relationship between Zen and poetry, which was initially discussed in thirteenth century China, when both Zen and poetry reached their golden era. In that era, it became popular for poets to draw insights from their Zen practice, and for Zen Buddhists to write poetry expressing their enlightenment, making Zen poetry an important genre of Chinese poetry. One of the most influential works of Chinese poetics is Chang-lang's Remarks on Poetry, in which Yan-yu, the author, makes significant statements about the intrinsic relationship between poetry and Zen. According to Yan-yu, Zen and poetry essentially seek the same kind of enlightenment, or wu in Chinese. Yan-yu contrasts the event of enlightenment, or wu with the mental activity of thinking, or si. According to Yan-yu, thinking is about the understanding of what has already been disclosed in books, principles, and things, while enlightenment is the initial disclosure. Understanding seeks to establish connections and coherence, while enlightenment renders the breakthrough. Enlightenment can be prepared for through intellectual understanding, as people who seek enlightenment often start with an intellectual understanding of the teachings. Nevertheless, enlightenment cannot be rendered through intellectual understanding, and cannot be expressed or transmitted through a logical system. When enlightenment takes place, it cannot be traced back to its origin, as if one forgets how it happens. In Yan-yu's words, enlightenment is like "those antelopes that hang by their horns, leaving no tracks to be followed" (Jiang, 1981). The occurrence of enlightenment is just like a sudden strike of poetic inspiration with a moment of awe, in which one cannot trace where it comes from, since all the available framework of references ceases to work. The meaning of a poem is placed in a new horizon and thus deferred. This renders a phantasmal illumination characteristic of both Zen and poetry. Yan-yu describes this aesthetic quality in this way:

The illumination is ethereal, limpid and sparking like a jingle in the sky, a color in light, a moon in the water, and an image in a mirror. Words can be exhausted, but the meaning goes on endlessly" (Jiang, 1981).

Poetry is composed of words, but the meanings of a poem are not signified by the conventional use of words which hides the poetic insight rather than reveals it. Poetry comes to life when the conventional meanings of words fade out without leaving any trace. Words still serve as signifiers, but the meanings of poetry go beyond what the conventional system of words can reach. The link between the conventional system and the poetic 
illumination becomes incomprehensible from any available positions; it is through a poetic leap one makes a crossover from the former to the latter.

Enlightenment is also a leap from everyday experiences in which the practice of Zen is rooted. The leap from the conventional system of words to a poetic insight corresponds to the leap from ordinary experiences to enlightenment. The latter emerges from the former without any trace, just like a lotus flower, the Buddhist icon, which is rooted in mud but comes out as a completely different being. When enlightenment happens, for a moment the experience may be inexplicable due to the lack of familiar signs. Zen master Dogen, in his well-known work, Shobogenzo, also likens enlightenment to "the moon reflected in water; the moon does not get wet, the water isn't broken" (Cleary, 1992). Dogen attempts to show that illumination emerges against the backdrop of ordinary experiences, and the two forms a vivid contrast, but there is no trace about how they are connected.

The leap constitutes the path for both enlightenment and poetry, as it crosses over, without any bridge, from the ordinary to the extraordinary, from the disclosed to the new disclosure. This process is like the procession of music, in which each note arises from the previous one, but does not derive from it, and there is no logical link between the two. Yan-yu states that this process "involves a different kind of faculty, which is not based on books, principles and conventions." (Jiang, 1981) Suzuki thinks that this "special faculty" is nothing but an "intuitive insight," which cannot be explicated in any logical term. In the essay titled "Zen and Haiku," Suzuki claims that this intuition is not only the gateway to enlightenment in Zen, but also the key to creativity in all Japanese art:

The idea that the ultimate truth of life and of things generally is to be intuitively and not conceptually grasped, and that this intuitive comprehension is the foundation not only of philosophy but of all other cultural activities, is what the Zen form of Buddhism has contributed to the cultivation of artistic appreciation among the Japanese people (Suzuki, 1973).

Here Suzuki agrees with Yan-yu that both enlightenment and poetry lie in the poetic leap which transverses from the disclosed world toward a new horizon. This poetic leap cannot be described or explained by any logical terms that functions to represent and organize what has been disclosed.

\section{Koan: The Poetic Device for Enlightenment}

The poetry of Zen refers not only to Zen poems, but also to Zen language in general. Zen language is characteristically the language of koan, the major form of Zen literature consisting of dialogues and stories of the Zen practitioner seeking enlightenment. The poetic nature of koan is commonly recognized among the practitioners, since many koans consist of poetic verses. It is also a common practice to write poetry as remarks on koans, and compile both together to be published. For example, in Bi-yan Lu, and Wu-men guan, the two major classical koan collections, there are poetic remarks and poems attached to each koan. However, there is an intrinsic relationship between koan and poetry, which is yet to be explored. Koan is the most important form of poetic language in Zen.

Each koan is an expression or a story of a breakthrough in the search for enlightenment. Known for its shocking power to assist people in attaining sudden enlightenment, it is also the major pedagogical device of the Zen's spiritual training and transmission. However, koan does not seem to fall into any genre of literature, and it does not fit any philosophical scheme. Therefore, it is perceived by many people as an enigmatic puzzle. The most striking characteristic of koan is its discord with any logic or linguistic rule, as Dumoulin noted, "In almost all the koans, the striking characteristic is the illogical or absurd act or word..... The koan are one great mockery of all the rules of logic" (Dumoulin, 1994). However, the absence of logic scheme is a part of the strategy to induce the experiences of enlightenment, as it shuts up all possible avenues to rationalization. Hori puts it this way:

The koan is said to pose to the Zen practitioner a paradox unsolvable by the rational, intellectualizing mind. Driven into an ever more desperate corner by his repeated futile attempts to solve what cannot be rationally solved, the practitioner finally breaks through the barrier of rational intellection to the realm of pre-conceptual and pre-linguistic consciousness variously called pure consciousness, no-mind, without-thinking, or emptiness (Hori, 2000).

Enlightenment is the illumination that arises from the emptiness of the mind. The traditional strategy to achieve the emptiness is through a philosophical deconstruction exemplified in Nagarjuna's philosophy. However, no matter how sophisticated a philosophical argumentation may be, it is conducted within a logical framework, which may facilitate a theoretical understanding of emptiness, but fall short of awakening the mind. Zen aims at 
the "sudden enlightenment" which demands that the deconstruction and illumination take place at the same time, and for that purpose, the rule of logic needs to be transcended for the experience of illumination to arise. The basic strategy of koan is to shift the discursive mode of discourse to a poetic mode of koan exchanges, which compels the speaker to let go of the logical position and framework of their speaking. When a disciple is attached to the intellectual approach to enlightenment, the remedy constructed by the master depends more on the extraordinary and artistic ways to say things, rather than on what he may say. Some koans provide compelling questions and puzzles that force the practitioners to suspend all intellectual schemes established in the mind. "What is your face like before you were born?" and "What is the sound of one hand clapping?" are two well-known examples of such questions that can bring people to a philosophical dead end where they see no way out unless they make a spiritual leap. A koan generally contains an intriguing device to cleanse and open the mind for the experiences of enlightenment to take place in so called a "sudden awakening." A typical koan consists of three episodes. The first one sets the stage usually situated in a pre-enlightenment condition, typically introduced by a question from a disciple who is often stuck on an intellectual approach to enlightenment. The second episode, usually performed by the master, brings the dialogue or the story to an impasse. The third episode shows or implies the breakthrough. The following is a typical example:

A disciple asked: "What did the patriarch, who came from the west, really mean in his teachings?" The master answered, "A cypress tree in the garden." The monk was baffled, "What you said is just a scene before our eyes; what I really mean to ask is about the essence of Zen," "ok then, please ask me again." "What did the patriarch from the west really mean in his teachings?" The master raised his voice, "The cypress tree in the garden." The monk was suddenly enlightened (Dao-yuan, 1965).

The first episode of the koan is introduced by a disciple who hopes to find an intellectual gist of the Buddhist teaching, that is, the conclusive answer to the question of enlightenment. The master could follow the intellectual approach and systematically deconstruct all the possible philosophical foundations about the idea of enlightenment, which is exactly what Nagarjuna did in the second century. However, the disciple would not be able to get out of the mode of logical thinking, even though he may be convinced of the theoretical deconstruction. Therefore, the master does not intellectually engage the disciple's question, but points to a scene of "a cypress tree in the garden" which seems to have nothing to do with what the monk asked. This approach is utterly against the logic that requires the answer to be relevant to the question. However, this strategy often works because it forces the disciples to give up their logical standpoint and seek different perspectives to see things, and different ways to say things, which is demanded by the venture of enlightenment.

A koan often starts with a question such as, "What is the way of enlightenment," "What is the Buddha nature," but the answers from the masters always seem logically absurd. Those questions, though seemingly fundamental, indicate a pre-enlightenment state, because they all problematically assume that enlightenment is an ultimate state, and they all anticipate definitive answers that can lead to enlightenment once for all. Those questions also indicate that those disciples are already exposed to some basic teachings of Buddhism, and are ready to be delivered to a new level. The question is how to make that happen. Zen masters often respond to those questions with such extravagance as, "Go ask that stump in the court" or "I will tell you if you can suck up the water of the western river." (Dao-yuan, 1965) The disciple may even receive surprises, such as a roar, a blow to the head with a stick, or simply silence. Poems are often introduced as the direct answers to those questions to dramatically change the mode of speaking. In one case, a monk asked the master Tian-zhu about the ultimate meaning of enlightenment, the master replies:

The blue sky is silent for thousands of years,

A moon emerges in morning breeze (D ao-yuan, 1965).

According to the methodology of Zen, masters are not supposed to prepare the way for the disciples, because the latter are expected to realize for themselves and in their own ways that Buddha nature lies in their individualities. The practitioners are supposed to find their own ways and make their own leaps based on their particular situations. Moreover, masters will eliminate the disciple's anticipation to depend on any external help, and deprive them of any expectation that there is an available path. They want to show the disciples that there is no available route between where they are and where they strive to be, between what they have already known and what they will come to know for themselves. The following koan story reflects this pedagogical strategy of Zen:

Hua-lin and Ling-yu were competing to be the leader of a group in their monastery. The master Bai-zhang then announced that whoever could make a good statement about the following situation would be the leader. He then pointed to a jar, "If you cannot call this jar as jar, what 
will you call it?" Hua-lin said, "You cannot call it stump either." When it was Ling-yu's turn, he stepped out and knocked the jar over. Master Bai-zhang smiled, "Ling-yu won this time" (Dao-yuan, 1965).

The statement "You cannot call it stump either" is a clever response to the test, but it does not go beyond the logical framework indicated by the statement that "you cannot call that jar a jar." The act of knocking over the jar does not indicate any definitive meaning. It may be interpreted that the jar is no longer a jar after it was knocked over, but it can mean something else, just like a poem, whose meaning cannot be pinpointed and exhausted. Ling-yu's act presents a picture that indicates a higher standpoint which can only be reached through a poetic leap, and that is why he wins the test. Obviously, the master's strategy includes two agendas. The first is to obliterate any available track between the present situation and the upcoming event of disclosure. The emptiness that disciples have to face in order to attain the illumination is the fact that there is no bridge, no path, and not even a map between where disciples start and where they want to arrive. Second, realizing that there is no available way to pass the emptiness the masters forces the disciples to make the poetic leap to greet the horizon of illumination. This situation can be best depicted by the well-known Zen verses, "Walk to the end of the stream/Sit and gaze where the clouds arise," written by Wang-wei, a Tang dynasty poet titled the poetic Buddha. After one is led to the end of the track, there is no longer a path to follow, and only at that moment, he sees the spectacular illumination. The following is another example of how a master pushes a disciple to the abyss of emptiness, and sees him rise from it on his own.

A monk could not reach enlightenment so he came to talk to a master. During the talking, the master suddenly grabbed the monk and yelled, "Hey, you are the one who stole my fruit." Monk said, "No I just came here and I have done nothing." "Yes, it is you, I am the witness, and here is the proof." The monk has nowhere to go, but keeps saying, "It is not me." The master shouted even louder, "It is you, it is not anybody else, and why do you deny yourself?" The monk was suddenly enlightened (Dao-yuan, 1965).

The monk could not reach enlightenment because of his attachment to his self-identity, although he may well understand the theoretic relationship between the Buddhist doctrine of no-self and the Zen's conviction that Buddha-nature is nothing but the nature of one's own mind. However, an understanding of the Buddhist philosophy about self does not render enlightenment, since enlightenment is not a result of understanding but an experiential breakthrough in which the self is cast out, but at the same time authentically manifested. The master has successfully provided a situation in which the monk can neither confirm nor negate the self-identity in any logical term. The monk had no path to walk through it but to make the poetic leap to reach a new spiritual height, in which the old image of self is shattered, and a new level of self-realization is reached. The concern about the "accusation" of his "guilt" immediately vanishes from his mind at that moment. The seemingly impossible puzzle of koan can only be solved in a poetic leap, in which both emancipation and illumination take place at the same time as a new disclosure arises from the mind that is cleared of the attachment to the disclosed. Koan is the poetic device that both expresses and facilitates such a leap.

The poetic leap, with both emancipation and illumination as its aspects, appears to allow the enlightened ones to say spontaneously whatever they want to say in whatever ways they like to say. However, this does not mean that enlightenment can be demonstrated by saying whatever one likes to say without considering anything that has been said. The speaking of enlightenment is not the sheer extravagance that only attempts to make a negation or difference of what has been said. The leap is neither derivative nor negation of what has been said. It must be accomplished in a genuine breakthrough into the new illumination, which is neither derived nor detached from what has been disclosed. This can be exemplified again by the Buddhist icon, the lotus flower, as a leap from the mud, but still rooted in it. The speaking of enlightenment on one hand transcends what has been said, but on the other hand illuminates the latter and fulfills its meaning. In order to make sense of the leap, the disclosure must consider the disclosed, although the link between the two can only be poetically conceived. The following koan reflects this situation.

Master Chi-ming asked a monk about the essence of Buddhism, and the monk answered:

No clouds gather on the top of the mountain,

The moon drops to the center of the ripple.

The master shouted, "I am asking you about the essence of Buddhism, who wants to hear such nonsense." The monk was a little nervous, "Can I have your instruction please?" "Sure, what is the question?" "What is the essence of Buddhism?" The master then recited, "No clouds gather on the top of the mountain, and the moon drops to the center of the ripple" (Pu-ji, 1967). 
The monk uses a poem to address the question about the essence of Buddhism, but simply throwing a poem does not necessarily demonstrate the leap to enlightenment. The master plays along with the monk's poem, initially rejecting it as "nonsense." This can be both a test and an effort to push the conversation to a new level. When the monk is waiting for the answer, to his surprise, the master returns to the poem initially given by the monk.

The poetic speaking of enlightenment is not meant to provide the ultimate answers to enlightenment, nor does it attempt to describe or represent enlightenment as a universal experience. It is the act of speaking that frees language from all established positions, frameworks, and logical rules, as the experiences of enlightenment emancipate and illuminates the mind. A quote from Kasulis is helpful to summarize the poetic transmission of Zen:

Zen Master does not speak, but, to use Heidegger's phrase, he lets "language itself speak." For the enlightened, speaking is itself a response to the directly apprehended situation. Language must be the vibrating of the undetermined without thinking within the conditions of the concrete occasion. Only when both aspects vibrate harmoniously does the language itself ring true (Kasulis, 1981).

The poetic speaking of enlightenment is neither derived nor the merely different from what has been said by their predecessors; nor is it a reflection of the present conditions of a practitioner. It situates in the present but reveals what is beyond it. When the speaking is detached from fixed positions and free from all boundaries, it can directly and unobstructedly respond to the mind and concrete situations from which the experiences of enlightenment may arise. The poetic mode of speaking emphasizes on how language unfolds itself rather than what need to be said, therefore it unfetters the spirit of language in its endless journey of disclosing.

Enlightenment is a generic term that indicates a breakthrough in transformation of the state of mind, reflected in the way of action, speaking, and being with others. Classical Zen literature, which is full of koans, poetry, and stories, does not provide a definition or any philosophical analysis of enlightenment. Suzuki and other thinkers such as the Kyoto School attempt to philosophize the experiences of enlightenment in an effort to introduce Zen Buddhism to the West. Although Suzuki remains one of the most influential Zen scholars, his conclusion that enlightenment is free from logic and even language is widely criticized by Western scholars who believe that linguistic conditioning plays an indispensable role in any form of experience. Accusations of logical inconsistencies and anti-intellectuality have been voiced against Suzuki (Faure, 1993). Suzuki's responses do not seem to be very helpful, as he argues that Zen was neither illogical nor anti-intellectual, but that it had its own type of logic, stemming from "pure experience" and differing from (or indifferent to) the dichotomous logic of Western philosophy (Faure, 1993). This argumentation is not acceptable to Western philosophers who may ask, "What is this kind of logic?" Suzuki's project may not stand up under the scrutiny and deconstruction of Western philosophical circles but his thoughts are significant as they are helpful in understanding the experiences of Zen, if we view Zen as poetic. Suzuki is not able to establish a theory of Zen, which, however, is not his responsibility since Zen does not allow such theory to be established. Zen is poetry, and from Zen's view, everything is poetry in which nothing can be established, but nothing can be argued as false. Zen is not interested in argumentation; it welcomes and tries to interpret all voices from the world. Blyth puts it this way:

Admitting then that Zen and poetry overlap to some extent, let us ask the question, is there anything which is poetical but has no Zen in it? Are there some non-poetical elements in Zen? Zen may seem to be pragmatic and practical, but it is also widely fantastic. It gives us the "sermons in stones and books in the running brooks" (Blyth, 1962).

From this view, everything poetic contains the message or spirit of Zen, and all the fresh experiences have elements of enlightenment. After correctly pointing out the inadequacy of logic in describing the experiences of Zen by scholars and practitioners like Suzuki, it appears that poetry and poetic dialogue provides the sources and new directions for a better understanding of the Zen experiences.

The central issue of Zen is about the understanding of enlightenment as the concrete experiences of the practitioners in their specific situations. Those experiences can be approached on various levels. Poetry is able to provide immediate expressions of the experiences. Literary criticism, as the direct interpretations of the poetry, offers an understanding of the particular experience. Philosophical discourses intend to construct a conceptual framework as an abstract representation of enlightenment. From a practical perspective of Zen, this abstract representation is not adequate because it cannot capture the concrete experiences of enlightenment, contrasting to the sense that meteorology can describe the change of weather and, therefore, be used to manipulate it. In other words, enlightenment cannot be attained or transmitted through an intellectual understanding of an abstract system. This limitation of abstraction or generalization is due to the chasm between particular and universal, 
between disclosed and undisclosed, and between the everyday experience and altered consciousness. First, Zen clearly indicates that enlightenment lies in the minds of individuals. It is not a universal consciousness, or a fixed experience given by any Buddhist founder; therefore, it cannot be adequately described and explained on an abstract level. Second, enlightenment points to a new horizon beyond the presently disclosed world, while any available logical system functions to represent and organize what has been disclosed in order to establish things or meanings. Therefore, one has to free himself from a logical framework to speak of enlightenment, and that is the case of koan exchanges. Third, in the culminating experiences of enlightenment, such as samadhi, the distinction between subject and object blurs; therefore, logical rules, which are generally conceived in the duality of subjectivity vs. objectivity, become no longer relevant. In order to attain enlightenment, one must cross the chasm. However, there is no "logical" link from one side to the other, as enlightenment cannot be logically derived from pre-enlightenment. The only path of enlightenment is through the leap.

The term leap is both a philosophical notion and a vivid metaphor for the experiences of enlightenment, the breakthrough in Zen practice. This term implies both the interruption from the disclosed (the leaped-from) and the emerging of the new horizon (the leaped-into), which parallels the two dimensions of Zen's enlightenment: emancipation and illumination. The meaning of enlightenment can then be conceived as the leaps in the journey of transformation of the mind, action, transmission, and morality.

The most critical question in this project is why we have to use the term poetic as the primary characterization of the leap. Although the leap cannot be adequately described and explicated in analytical terms such as cause and effect, it can be metaphorically captured in poetry, which is considered, by thinkers such as Heidegger, as a primordial language. Characterizing enlightenment as poetic leap affirms the relevancy of language in Zen's experiences, and thus resolves the debate about whether the experiences of enlightenment are linguistically conditioned. We say that enlightenment is a poetic leap not only because poetry can capture or express the leap but also because poetry constitutes the cultural, spiritual, and linguistic conditions that foster enlightenment. Zen's koan and the Confucian system of "poetic teaching" are the examples of poetry as the path or the device for achieving enlightenment and goodness.

Furthermore, the term leap captures (if not defines) not only enlightenment but also the essence of poetry as well, as both Chinese and Western traditions of poetics use ideas implied in the notion of leap to understand the nature of poetry, which is as difficult to define as enlightenment. The leap entails three things: the place to leap from, the horizon to leap into, and the emptiness that lies in between. Poetics of both the East and West have discussed these three aspects as the essence of poetry. According to Heidegger, poetry is "the inaugural naming of Being and of the essence of all things ... which for the first time brings into the open all that which we then discuss and deal with in everyday language" (Adams, 1986). This "inaugural naming" is the disclosure of new horizon into which the leap leads. This poetic disclosure gives rise to a sense of de-familiarization because it takes the mind away from where one used to dwell the place where one will leap from. As Heidegger puts it:

It is due to art's poetic nature that, in the midst of what is, art breaks open an open place, in whose openness everything is other than usual . . Everything ordinary and hitherto existing becomes an un-being (Bruns, 1989).

Emptiness is the ground and space for the leap. The leap springs from and crosses over the nothingness that characterizes both enlightenment and poetry. Look at the following couplet again:

A line of wild ducks are flying over the field,

She pins chrysanthemums all over her hair.

The poems flows well from the first line to the second one, forming a good picture, but nothing can be said about how the first line poetically leads to the second one. The poem is driven by an impulse arising from emptiness, as there is no traceable transition between the two lines. That is why Yan-yu, one of the most influential Chinese thinkers of poetics in Tang dynasty, believes that realization of emptiness is the essence of both poetry and enlightenment of Zen. Heidegger also believes that the poet's vocation lies in the sense of the lack. For example, he thinks that it is the absence of god that inspires poets to name the Sacred (Froment-Meurice, , 1998).

Indeed, deeming enlightenment as the poetic reflects the Chinese canonical statement: Shi yan zhi; ge yong yan, literarily translated as "poetry speaks the mind, and songs perpetuate language," which characterizes the essence of Chinese literary and spiritual tradition. Poetry reveals the journey of the mind as songs perpetuate the flowing of words. This statement has become a slogan in both the Chinese literary and spiritual tradition, as it has been widely quoted in Chinese texts of philosophy, religion, and literary theory from the earliest classics to contemporary works. The way songs keep the word's flowing corresponds to the flowing of music in which each 
note springs but does not derive from the previous one. There is "emptiness" between two adjoining notes, which must be crossed over in a leap. The travel of the mind resembles the flowing of poetry, in which a new line arises but at the same time breaks free from the previous one. To learn poetry is to experience the spirit of words as it makes spontaneous leaps from one line to another without disturbing the natural flow. This course corresponds to the poetic movement of the mind letting it go unfettered without transgressing the line.

The enlightened mind is a poetic mind which constantly "travels" toward new horizons, making leaps to transform and refresh one's perspective on the world. The enlightened one speaks poetically as he is able to rise above his habitual positions and the established logical rules in his endless search for new modes of speaking that bears witness to enlightenment. The enlightened one acts poetically as he is emancipated from his existential conditions and is able to make moves to transcend his karma or causality, which would otherwise determine his actions in the world and interactions with others. The deeds of the enlightened one may appear eccentric, but are poetically good, as they are beyond the conventional criterion of good and evil.

\section{Poetry Speaks Truth}

We have discussed the existential and moral significance of enlightenment in light of a Zen poetics. One more question can still be asked: what is the truth value of enlightenment as the poetic leap? Traditional Western philosophy believes that truth lies in either subjectivity, objectivity, or something in between. This assumption generally renders truth on the basis of the correspondence between subjectivity and objectivity, or the coherence made in subjectivity. Zen does not believe the substance of subjectivity or objectivity, as samadhi transcends the duality as subject and object merges. It therefore appears that Zen does not provide a philosophical basis for truth value.

The truth value of Zen, however, can be conceived in terms of poetry. Heidegger's statement that "Poetry speaks truth," which is reiterated in Poetry, Language Thought, casts a light on this matter. What Heidegger means by truth in this statement marks a radical departure from the traditional understanding of truth. According to Heidegger, truth is the disclosure of Being, in which the opposition between subject and object has been mediated in the notion of Dasein, being-in-the-world, which is neither subjective nor objective. Therefore, Heidegger's definition of truth as the event of disclosure escapes the opposition between object and subject. The traditional conception of truth requires some sort of independent rational criteria to measure the correspondence between the ideas and the reality or the inner coherence of the ideas. This is clearly not provided in Heidegger's account of truth. To Heidegger such approach to truth is derivative and secondary. The traditional implication that truth is about the true or false is not relevant in Heidegger's thought. The polarity of truth and falsity is replaced by Heidegger as disclosing and concealing. The disclosing is possible and meaningful exactly because of the condition of concealment. To bring something into the light is to cast an aspect of it into shadow. Therefore, "Dasein is equally in truth and untruth (Heidegger, 1996).

The traditional understanding of truth as agreement or coherence also assumes that truth, as the content of the disclosed, can be isolated from the process of disclosing. The location of truth, according to this view, is in the proposition or judgment of being true or false. Again, Heidegger thinks that this is only the derivative or secondary meaning of truth. As he put in Being and Time, the primordial truth is the ontological movement of Being:

This possibility means that Dasein discloses itself to itself in and as its ownmost potentiality of Being. This authentic disclosing shows the phenomenon of the most primordial truth in the mode of authenticity, the most primordial disclosing in which Dasein can be as potentiality-of-being in the truth of existence (Heidegger, 1996).

Truth in its primordial sense is the ongoing event of disclosing. The content, as the disclosed, is true only in the secondary or derivative sense. Therefore, the primordial truth lies in the authenticity of human existence rather than in the system of propositions or judgments, which is considered the derivative. We have discussed how Heidegger differentiates two modes of language corresponding to the two modes of Being, with the poetic language aligned to the authenticity of Being. These two modes of Being, language, and truth provide the possibility for the transformation of human beings, which is analogous to the Buddhist venture of enlightenment. In his later works, Heidegger mentions that the event of disclosing through language is also the event of transformation, as he put it in On the Way to Language:

We can experience language and by doing so language will touch our innermost existence. We who speak language may thereupon become transformed by such experiences (Heidegger, 1996). 
It is through poetry, the primordial language, that the authenticity of Being becomes manifested. "Poetry speaks truth" then means that poetry authentically discloses Being. Heidegger's search for truth turned out to be a "calling for a poetic transformation proper to human beings" (Anderson, 1996). The primordial truth as the disclosure of Being and transformation of Dasein is, therefore, a poetic truth. This thought agrees with Zen's idea that enlightenment is an endless poetic journey of exploration and transformation, rather than a final state of the mind. This journey does not render the truth in terms of the coherence of subjectivity or the correspondence between subjectivity and objectivity. Instead, both subjectivity and objectivity fade away as they merge in samadhi, a culmination of the mind in its journey of transformation, which is poetically depicted in the ten ox-herding pictures.

This journey can be captured poetically because it is essentially poetic in terms of that it corresponds to the process of learning poetry in light of Chinese poetics. For example, Wang Guo-wei, one of the most influential classical thinkers of poetics, proposes three poetic visions, or jing jie in Chinese, as the phases of learning poetry. These three visions resemble the journey of Zen practice as depicted in the ten ox-herding pictures. Wang uses his three poems to capture these three visions, which are in accordance with the methodology of Chinese poetics in claiming that the best way to discuss poetry is through poetry. The first poetic vision is represented by the following poem:

Last night the west wind shriveled the jade green tree.

Alone I climb the high pavilion

And Gaze to the end of the road at the sky's edge (Yeh, 1998).

According to Wang, this is the first phase of poetic experience in learning poetry, in which a poet genuinely realizes the tension between the self and the world. He is no longer content with his existence in the world, so he wants to rise above in searching for the path of the poetic journey. This vision, in Wang's words, can be characterized as "the vision of the outstanding self," or you wo zhi jing. This vision corresponds to the first ox-herding picture, in which the herdsman experiences bewilderment in an existential crisis. The second poetic vision is represented by the following couplet:

My girdle keeps growing looser, but I've no regret,

It's worth it, wasting away for him (Yeh, 1998).

"Him" here means the poetic insight that a poet strives to attain, but in this process the sense of self as the seeker is emptied or "wasting away." Compared with the practice of Zen, this vision can summarize the spiritual stages depicted from the second to the eighth ox-herding picture, in which the subject engages and wrestles with the object until the distinction of the two is transcended in samadhi or emptiness. This scenario, in Wang's word, is "the vision of self is vanishing," the second phase of learning poetry. The third vision is represented in the following poem:

A thousand and hundred times I looked for him in the crowd,

Then suddenly, as I turned my head,

There he was where the lanterns were few (Yeh, 1998).

The poetic insight suddenly strikes the mind of a poet in the same fashion the illumination of enlightenment occurs in the practice of Zen. Therefore, as discussed earlier, Yan-yu, another prominent thinker of poetics, thinks that poetic insight is nothing but the illumination rendered by enlightenment. Emerging from the emptiness is the new face of the world illuminated by the poetic insight obtained in the venture. The sense of self now returns not as the transcendental ego, but as a poetic character "mingled" with a poetically illuminated "crowd" in the world. Another of Wang's poems vividly captures this scenario:

Striving to ascend the highest peak for a close look at the white moon,

I chanced to open a celestial eye and look down to the Red Dust,

My own self alas there among those I see (Yeh, 1998).

This vision corresponds to the ninth and the tenth ox-herding pictures, in which the whole world is illuminated in enlightenment and the enlightened one returns to society to mingle with people.

The poetic truth conceived in poetry and enlightenment does not render the coherence in or the correspondence between subjectivity objectivity; instead, it reveals the insubstantiality of the demarcation. Poetry does not establish anything; it is the presentation itself rather than what is represented in poetry that constitutes poetry and its significance. The truth in this poetic sense has no destined closure, historical authorship, or prescribed 
structure. It can be poetically transmitted, but cannot be universally verified based on coherence, correspondence, or pragmatism. Zhuang-zi is able to illustrate this profound idea with a self-explanatory parable about a giant gnarled tree on a roadside and a goose that cannot cackle:

Zhuang-zi was walking on a mountain, when he saw a great tree with huge branches and luxuriant foliage. A woodcutter was resting by its side, but he would not touch it, and, when asked the reason, said, that it was of no use for anything. Zhuang-zi then said to his disciples, 'This tree, because its wood is good for nothing, will succeed in living out its natural term of years.' Having left the mountain, the Master lodged in the house of an old friend, who was glad to see him, and ordered his waiting-lad to kill a goose and boil it. The lad said, 'One of our geese can cackle (upon seeing strangers), and the other cannot; which of them shall I kill?' The host said, 'Kill the one that cannot cackle.' Next day, his disciples asked Zhuang-zi, saying, 'Yesterday the tree on the mountain would live out its years because of the uselessness of its wood, and now our host's goose has died because of its want of power (to cackle); which of these conditions, Master, would you prefer to be in?' Zhuang-zi laughed and said, 'I would prefer to be in a position between being fit to be useful and wanting that fitness' (Legge, 1962).

Indeed we cannot judge that tree by its uselessness from man's perspective, since it is exactly because of its worthlessness to man that the tree survives to its natural term. However, the goose is killed because it fails to be useful. Zhuang-zi simply indicates that it is impossible to have a universal basis to verify the value of "truth." With authorship, structure, and verifiability rendered irrelevant, truth loses its delimitation and attains its broadest scope: whatever people find disclosing or enlightening creates a moment of truth for them, and suddenly all is good and everything rings true. For example, master Bao-Ji had his first insight of Zen during a bargaining conversation with a butcher in a meat market, and got enlightened later by listening to a the funeral chanting (Qu, 1992). Master Lou-zi was enlightened when he, passing by a brothel building, overheard a prostitute's complaint about her clients, so he renamed himself as Luo-zi, taking the name of the building in Chinese (Qu, 1992). A well-known poem by Su dong-po reads:

The sounds of brook is Buddha's voice.

The gleams on water and the colors of mountain are Dharma's face

Overnight they transmitted thousands of Sutras

How can I share them with people tomorrow? (Yang, 1998).

Sutra used to mean the teachings of the historical Buddha, but in the poeticization of Zen, the whole world becomes sutra as it can disclose meanings and transform lives. Therefore, Dogen says, "What we mean by the sutras is the entire universe itself, mountains and rivers and the great earth, plants and trees ..." (Loy, 1993). Indeed, the primordial truth lies in the endless journey of the interpretation of the world, and according to Zen as well as Heidegger, this interpretation is essentially poetic. The following Zen koan can summarize what has been said in this project:

A group of learned monks came to visit master Da-zhu, and one of them asked, "I have a question in my mind; will you answer that?" Da-zhu replied, "The moon casts its phantom into the lake, and dances at her will with all the waves." Taking it as permission, the monk asked, "How to become a Buddha?" The master responded, "Across the lake, who are those other than a group of Buddha?" Everybody was astonished. After a silence, a monk asked, "What doctrine do you use to deliver people?" Da-zhu answered, "I've got no doctrine to use and no people to deliver." One monk became a little frustrated, and said, "All you Zen masters are talking like that." Da-zhu then asked, "What doctrine do you use to deliver people?" The monk answered, "I use Diamond Sutra." "How many times have you taught that sutra?" "More than twenty times." "Do you know who originally preached that sutra?" "You must be kidding; everybody knows that the sutra was given by the Buddha." Da-zhu smiled, "The Buddha said in the Diamond Sutra that "Anyone who claims that I have ever preached any doctrine is committing a blasphemy against me.' But I know you cannot say that the sutra is not given by the Buddha, because that will be considered a blasphemy against the sutra. Now you put yourself in a situation where you have to commit a blasphemy either against the Buddha or against the sutra." All are silenced (Dao-yuan, 1965).

Before enlightenment, mountain is the mountain and water is the water, and there is a clear distinction between enlightenment and non-enlightenment, between Buddha and normal people. At this stage, practitioners strive for 
the leap into enlightenment. When the leap is made upon enlightenment, the views dramatically change; all logical schemes and conventional frameworks collapse and distinctions between things become unsubstantiated, in which enlightenment is not different from non-enlightenment, and Buddha is not better than a ordinary person. Obviously one cannot practically live in the shared world when obsessed with this "enlightened" vision, which disables the distinction between mountain and water. Moreover, this alleged "enlightened" vision cannot be spoken, which gives rise to a logical and practical dilemma of "realizing nothingness." The way out of the dilemma lies in the critical question: what is the difference between the two kinds of views, namely the enlightened one and the unenlightened one. We can only approach this question from two perspectives (which will be the perspectives about perspectives). From the conventional perspective or shu jing, there are two logically different visions, the enlightened one and the unenlightened one. But from the perspective of enlightenment or wu jing, there is no difference between the two visions; therefore, there is only one kind of vision after enlightenment, in which "mountain is not the mountain and water is not the water," while at the same time "mountain is again the mountain, and water is again the water." I am who I am, but at the same time, I am not who I am. Zen allows one to simultaneously have different perspectives on the world and the self. This kind of vision can only be spoken of poetically because it has gone beyond logic. This is the poetic leap that a practitioner realizes in enlightenment, the leap that uplifts one's spirit while at the same time enables one to dwell in the world and mingle with people with their extraordinary visions.

\section{Conclusion}

Poetry has become a major means and source for the spiritual transmission of Zen, and it is common for Zen practitioners to write poetry to express their experiences and illustrate their insights. However, the intrinsic relationship between poetry and the venture of enlightenment has not been extensively discussed. People generally believe that poetry is just a means to convey the experiences of Zen. For example, a well-circulated slogan says, "Poetry adds flowery brocade to Zen, and Zen provides the edge of insight to poetry" (Sun, 1993). This belief assumes a dualistic relationship between Zen and poetry, which reduces poetry to an external outfit of Zen. Many Zen practitioners believe that enlightenment is like the moon, and poetry, as a form of language, is like the finger which points to the moon. The moon and finger metaphor may suit the relationship between the signified and signifier, but it is not an appropriate metaphor to indicate the relationship of enlightenment and poetry, because poetry is both the signifier and the signified. Blyth puts it this way:

It is a great mistake to think of the words of a poem as signs or symbols of some invisible mental experience ... After all, the finger does not point to the moon; the finger is the moon. The poetic experience is not wordless, any more than the soul is bodiless. In the original poetical experience the words are not yet separated from the experience (Blyth, 1994).

The poetic transmission of Zen is in contrast to the discursive discourse based on an established logical system. The poetic speaking is not rooted in what has been said by the founders, nor governed by logical rules, and nor anchored to any fixed positions. In the practice of Zen, the poetic speaking directly responds to concrete situations, or spontaneously expresses the experiences of enlightenment of individuals.

The historical Buddha once gave a sermon of silence, which has been broken by the poetry of Zen.

\section{References}

Adams, H., \& Leroy, S. (Eds.) (1986). Critical Theory since 1965. Tallahassee: Florida State University Press.

Anderson, T. T. (1996). Through Phenomenology to Sublime Poetry: Martin Heidegger on the Decisive Relation between Truth and Art. Research in Phenomenology, 26, 198-229. http://dx.doi.org/10.1163/156916496X00102

Blyth, R. H. (1962). Zen and Zen Classics (Vol. 6). Tokyo: Hokuseido Press.

Blyth, R. H. (1994). The Genius of Haiku: Readings from R.H. Blyth on Poetry, Life, and Zen. England: British Haiku Society.

Bruns, G. L. (1989). Heidegger's Estrangements: Language, Truth, and Poetry in the Later Writings. New Haven: Yale University Press.

Cleary, T. (1992). Shobogenzo: Zen Essays by Dogen. University of Hawaii Press.

Dao-yuan. (Eds.) (1965). Jin-De Chuan-Deng Lu. Tai Bei: Zhong Wen Tang.

Dumoulin, H. (1994). Zen Buddhism: A History (Vol. I). Beziger Publishing Co.

Faure, B. (1993). Chan Insights and Oversights: An Epistemological Critique of the Chan Tradition. Princeton, 
New Jersey: Princeton University Press.

Froment-Meurice, M. (1998). That Is--to Say: Heidegger's Poetics. Stanford, Calif.: Stanford University Press.

Heidegger, M. (1971). On the Way to Language (1st ed.). New York: Harper \& Row.

Heidegger, M. (1996). Being and Time: A Translation of Sien Und Zeit. Trans. Stambaugh, Joan. Suny Series in Contemporary Continental Philosophy. Albany: State University of New York Press.

Hori, S. V. (2000). Koan and Kensho in the Rinzai Zen Curriculum. In Z. Buddhism (Ed.), The Koan: Texts and Contexts. Heine, Steven and Dale S. Wright. Oxford ; New York: Oxford University Press, xii, 322.

Jiang, Z. (Ed.) (1981). Zhong Guo Shi Hua Chi Dian. Bei Jing: Bei Jing Publisher, Kasulis.

Kasulis, T. P. (1981). Zen Action/Zen Person. Honolulu: University Press of Hawaii.

Legge, J. (1962). Sacred Books of China: The Texts of Taoism. New York: Dover.

Loy, D. (1993). Indra's Postmodern Net. Philosophy East \& West, 43, 481-510. http://dx.doi.org/10.2307/1399579

Pu-ji. (1967). Wu Deng Hui Yuan. Tai-bei: Xing Wen Feng Publisher.

Qu, R. (Ed.) (1992). Zhi Yue Lu. Tai Bei: Xin Wen Feng Chu Ban She.

Sun, C. (1993). Shi Yu Chan. Tai Bei: Dong-Tu Tu Shu Gong Shi.

Suzuki, D. T. (1962). The Essentials of Zen Buddhism (1st ed.). New York: Dutton.

Suzuki, D. T. (1969). The Zen Doctrine of No-Mind: The Significance of the Sutra of Hui-Neng. London: Rider.

Suzuki, D. T. (1973). Zen and Japanese Culture (3rd ed.). New York: Princeton University Press.

Thomas P. (1981). Zen Action/Zen Person. Honolulu: University Press of Hawaii.

Wright, D. S. (1992). Rethinking Transcendence: The Role of Language in Zen Experience. Philosophy East and West, 42, 113-138. http://dx.doi.org/10.2307/1399693

Yang, Y. (Ed.) (1998). Wu Yu Mei: Chan Shi Xin Yi. Cheng Do: Shi Chuan Ren Min Chu Ban She.

Yeh, C., \& James, R. H. (1998). Studies in Chinese Poetry. Cambridge: Harvard University Press. 